\title{
ESTUDO DE PADRONIZAÇÃO DE EXTRATOS DE Anacardium occidentale L. NA PESQUISA E DESENVOLVIMENTO DE FITOTERÁPICOS GIARDICIDAS*
}

\author{
STUDY OF STANDARDIZATION OF Anacardium occidentale L. EXTRACTS IN RESEARCH \\ AND DEVELOPMENT OF GIARDICIDALS HERBAL
}

ESTUDIO SOBRE ESTANDARIIZACIÓN DE EXTRATOS DE Anacardium occidentale L. EN
LA INVESTIGACIÓN Y DESARROLLO DE FITOTERÁPICOS GIARDICIDAS

\author{
Farid Antônio Trabulsi Filho \\ Kécia Casé de Sousa Andrade \\ Elayne Costa da Silva \\ Abigail Trindade Oliveira Castro \\ Marisa Cristina Aranha Batista \\ Maria Nilce de Sousa Ribeiro \\ Flavia Maria Mendonça do Amaral
}

\begin{abstract}
Resumo: Fitoterápicos são medicamentos amplamente utilizados, constituindo segmento da indústria farmacêutica em larga expansão na atualidade, exigindo garantia na oferta de produtos eficazes e seguros. Nesse sentido, esse estudo objetiva aplicar e/ou desenvolver metodologia analítica para a padronização de extratos de Anacardium occidentale L. (família Anacardiaceae), conhecida como cajueiro, empregando ensaios químicos e biológicos de atividade giardicida. Folhas de Anacardium occidentale foram coletadas em habitat natural, submetidas à secagem e moagem, seguida da obtenção dos extratos hidroalcoólicos com emprego de planejamento fatorial dos fatores: operação de extração (maceração, percolação e aparelho Soxhlet) e hidromódulo (1:8, 1:10 e 1:12), submetidos a análise sensorial, análise química qualitativa e quantitativa, avaliação da atividade antioxidante e giardicida. Os resultados evidenciaram diferenças de cor entre os extratos obtidos por diferentes procedimentos, indicando presença de fenóis simples, flavononois, taninos catéquicos, alcaloides, catequinas, flavononas, cumarinas, esteroides e saponinas; com variação quantitativa entre as amostras analisadas, sendo evidenciada também diferenças na atividade antioxidante e atividade citotóxica contra Giardia lamblia, mostrando que as variáveis empregadas nesse estudo influenciam na obtenção dos extratos hidroalcoólicos das folhas de Anacardium occidentale e, consequentemente, nos rendimentos e atividades antioxidante e giardicida.
\end{abstract}

Palavras-chave: Anacardium occidentale L. Controle de qualidade. Padronização de extratos. Giardia lamblia.

\begin{abstract}
Herbal medicines are medicines used widely worldwide, constituting one of the segments of the pharmaceutical industry at large scale, requiring guarantee the supply of effective and safe products. Accordingly, this study aims to apply and/or develop analytical methodology for the standardization of extracts of Anacardium occidentale L. (family Anacardiaceae), known as cashew nuts, employing chemical and biological assays of giardicida effect activity. Anacardium occidentale L. leaves were collected in natural habitat, subjected to drying and grinding, followed by obtaining of extracts alcoholbased products with factorial planning of job factors: operation of extraction (maceration, percolation and Soxhlet apparatus) and hidromódulo (1:8, 1:10 and 1:12); subjected to sensory and chemical analysis, determination of phenolic compounds and evaluation of antioxidant activity and giardicida effect. The results show differences in colour between the extracts obtained by different procedures; indicating the presence of simple phenols, flavononois, catéquicos, alkaloids, tannins, catechins, flavononas, coumarins and saponins, steroids; with quantitative variation among the examined extracts; show also differences in antioxidant activity and presence of cytotoxic activity against Giardia lamblia in one of extracts alcoholbased products, showing that the variables used in this study influence in getting the alcohol-based products extracts of leaves of Anacardium occidentale and consequently on their incomes and their giardicida effect and antioxidant activities.
\end{abstract}

Keywords: Anacardium occidentale L. Quality control. Standardization of extracts. Giardia lamblia.

Resumen: Los fitoterápicos son medicamentos de una amplia utilización, constituyendo el sector de la industria farmacéutica en grande expansión en la actualidad, exigiendo una garantia en la oferta de productos eficaces y seguros. Asi, este estudio busca aplicar y/o desarrollar una metodologia analítica para la padronización de extratos de la planta Anacardium occidentale L. (familia Anacardiaceae), conocida como cajueiro, utilizando ensayos químicos y biológicos para actividad giardicida. Fueron colectadas hojas

Trabalho premiado durante o XXIV Encontro do SEMIC, realizado na UFMA entre os dias 05 a 08 de novembro de 2012.

*Artigo recebido em dezembro 2012

Aprovado em fevereiro 2013 
de Anacardium occidentale en habitat natural, sometidas a secura y a molienda, para la posterior obtención de los extratos hidroalcohólicos através del empleo de planeamiento factorial de los factores: operación de extracción (maceración, percolación y aparato de Soxhlet) y el hidromódulo (1:8, 1:10 y 1:12), sometidos a análisis sensorial, análisis químico cualitativo y cuantitativo, evaluación de la actividad antioxidante y giardicida. Los resultados mostraron diferencias de color entre los extractos obtenidos através de diferentes procedimientos, indicando la presencia de fenoles simples, flavononois, taninos catequínicos, alcaloides, catequinas, flavononas, cumarinas, esteroides y saponinas; con una variación quantitativa entre las muestras analizadas, siendo observadas también diferencias em las actividades antioxidante y citotóxica contra Giardia lamblia, mostrando que las variables utilizadas em este estudio tienen influencias em la obtención de los extractos hidroalcohólicos de las hojas de Anacardium occidentale y, por consecuencia, em los rendimientos y actividades antioxidante y giardicida.

Palabras clave: Anacardium occidentale L. Control de Calidad. Estandarización de extractos. Giardia lamblia.

\section{INTRODUÇÃO}

Plantas medicinais são fontes potenciais de moléculas bioativas com estrutura diferenciada e mecanismo de ação inovador, característica que tem motivado a indústria farmacêutica em incentivar pesquisas visando desenvolvimento de medicamentos fitoterápicos (ELISABETSKY, 2004).

O uso de fitoterápicos na medicina humana quer seja como prática tradicional, complementar ou alternativa à alopatia, vem sendo estimulado legalmente no Brasil dado o reconhecimento dos benefícios garantidos pelo uso seguro, eficaz, qualificado e racional (BRASIL; 2006). Esse estímulo é fundamentado nas vantagens largamente atribuídas aos fitoterápicos como custos reduzidos e valorização das tradições populares, bem como a comprovação, através dos avanços das pesquisas, dos efeitos sinérgicos decorrentes dos vários constituintes químicos presentes em uma espécie vegetal e da associação de mecanismos por constituintes agindo em alvos moleculares diferentes, contribuindo na eficácia terapêutica (YUNES; CALIXTO, 2001; LAPA et al., 2004; ELISABETSKY, 2004; SIXEL; PECINALLI, 2005).

A Organização Mundial da Saúde (OMS) acredita que, atualmente, a prática do uso medicinal de plantas representa a principal opção terapêutica de aproximadamente $80 \%$ da população mundial, sendo comprovada a ascensão mundial do mercado de fitoterápicos movimentando cerca de US\$ 22 bilhões por ano. No Brasil é estimado que o comércio de fitoterápicos represente $5 \%$ do mercado total de medicamentos, avaliado em mais de US\$ 400 milhões (PINTO et al., 2002).

A validação de espécies vegetais, principalmente as de amplo emprego na prática popular, selecionadas por estudos etnofarmacológicos, constitui uma estratégia na busca de novos agentes terapêuticos. Tanto a pesquisa bibliográfica, quanto a informação popular servem de base para a indicação da atividade farmacológica (LAPA et al., 2004).

Anacardium occidentale L., espécie pertencente à família Anacardiaceae, conhecida popularmente como cajueiro, representa uma das 21(vinte e uma) espécies do gênero Anacardium, todas de ocorrência tipicamente tropical (LIMA, 1988), constituindo a única espécie cultivada e a de maior dispersão (MORTON, 1961; JOHNSON, 1973; MITCHELL; MORI, 1987).
A espécie é perene e predominantemente alógama, com alto grau de heterozigose das populações naturais, já que o processo natural de propagação é por sementes (BARROS, 1988; BARROS; CRISÓSTOMO, 1995). A distribuição natural desta espécie, no entanto, pode ser confundida pela dispersão por cultivo, uma vez que, enquanto o principal centro de diversidade do gênero seja a região amazônica, com um centro secundário de diversidade nos cerrados, o cajueiro pode ser encontrado em diversos ecossistemas do Norte e Nordeste do Brasil (DUQUE, 1962; MITCHELL; MORI, 1987; LIMA, 1988; BARROS NETO; SCARMINIO; BRUNS, 1995).

É utilizado na medicina tradicional, principalmente no nordeste brasileiro com efeitos terapêuticos como: alívio de dor de dente, antiinflamatório para gengiva e garganta, bronquites, artrites, cólicas intestinais, icterícia, contra diabetes, asma e, até mesmo, usado como afrodisíaco (MORAIS et al., 2005; AGRA; FRANÇA; BARBOSA FILHO, 2007).

Estudos têm comprovado diversas atividades farmacológicas, tais como: antiinflamatória (OLAJIDE et al., 2004; FALCÃO et al., 2005), antidiabética (KAMTCHOUING et al., 1998; BARBOSA-FILHO et al., 2005), inibidor da enzima acetilcolinesterase (BARBOSA-FILHO et al., 2006), sendo comprovado, ainda, que substâncias isoladas do fruto inibem a tirosinase (KUBO; KINST-HORI; YOKOKAWA, 1994).

A inclusão da espécie Anacardium occidentale na Relação Nacional de Plantas $\mathrm{Me} \neg$ dicinais de Interesse ao Sistema Único de Saúde (RENISUS), contendo 71 (setenta e uma) espécies vegetais com potencial de avançar nas etapas da cadeia produtiva e de gerar produtos de interesse ao Sistema Único de Saúde (SUS), com finalidade de subsidiar o desenvolvimento da cadeia produtiva, visando, ainda, indicar espécies vegetais para o desenvolvimento de estudos e pesquisas que possam subsidiar a elaboração da Relação Nacional de Plantas Medicinais e Fitoterápicos (RENAFITO), o desenvolvimento e a inovação na área de plantas medicinais e fitoterápicos, são elementos que devem incentivar o desenvolvimento de estudos com a espécie. 
Giardíase é uma infecção intestinal causada pelo protozoário flagelado Giardia lamblia (sinonímia: Giardia intestinalis, Giardia duodenalis), com ampla distribuição mundial e elevadas taxas de prevalência (THOMPSON; HOPKINS; HOMAN, 2000; ADAM, 2001; SOGAYAR; GUIMARÃES, 2005). A incidência mundial, segundo a Organização Mundial de Saúde, é de cerca de 500 mil novos casos por ano (WHO, 2009).

O metronidazol é o tratamento de primeira escolha da giardíase, sendo ainda empregadas outras drogas, como: secnidazol, tinidazol, ornidazol, albendazol, mebendazol, furazolina, quinacrina e benzimidazóis, em tratamento único e/ou combinações terapêuticas. Entretanto, esses quimioterápicos ocasionam efeitos adversos como distúrbios gastrintestinais, náusea, dor de cabeça, leucopenia e gosto desagradável, podendo desencadear, ainda, efeitos neurotóxicos, ataxia, convulsão e vertigem; com consequente interrupção do tratamento (HERESI; MURPHY; CLEARY, 2000; HARRIS; PLUMMER; LLOYD, 2001).

Mesmo com o vasto arsenal de fármacos sintéticos empregados na quimioterapia da giardíase, é observado o desenvolvimento da resistência do parasita, com aumento significativo de pacientes refratários, tanto no tratamento com emprego de única droga, como nos esquemas com alternância e/ou associação de drogas complementares (UPCROFT et al., 1990; UPCROFT.; HEALEY; UPCROFT, 1993; UPCROFT; CHEN; UPCROFT, 1996; 1999; ARGÜELLO-GARCÍA et al., 2004).

Diante do exposto, esse estudo visa ao desenvolvimento e aplicação de metodologia analítica para a padronização dos extratos de Anacardium occidentale L., empregando ensaios químicos e biológicos de atividade giardicida, visando contribuição efetiva na obtenção de novas alternativas terapêuticas no combate à giardíase.

\section{METODOLOGIA}

\subsection{Coleta, secagem e moagem do mate- rial vegetal}

As folhas de Anacardium occidentale foram obtidas através de coletas manuais realizadas no CAMPUS da Universidade Federal do Maranhão, localizado no Bacanga, em São Luís, Estado do Maranhão, segundo as determinações estabelecidas na literatura especializada (OLIVEIRA; AKISUE; AKISUE, 1991; VON HERTWIG, 1991; COSTA, 1994; BOTSARIS, 1995). A identificação botânica foi realizada no Herbário "Ático Seabra" da Universidade Federal do Maranhão, onde a exsicata está depositada sob número 1050/SLS017213. O material vegetal foi submetido à secagem em estufa com circulação de ar, em temperatura limite máxima de $38^{\circ} \mathrm{C}$; seguida de trituração em moinho de facas, obtendo pó moderadamente grosso (tamanho inferior a $710 \mu \mathrm{m}$ e superior a $250 \mu \mathrm{m}$ ) (FARMACOPÉIA BRASILEIRA, 2010), mantido em saco plástico estéril, identificado e bem fechado, até as análises.

\subsection{Obtenção dos extratos hidroalcoóli- cos das folhas de Anacardium occidentale L.}

O material seco e moído (65 g) foi extraído, em separado, por maceração, percolação e em aparelho de Soxhlet com etanol a $70 \%$, por período médio de 15 (quinze) dias para maceração, 03 (três) dias para percolação e 01 (um) dia para Soxhlet. Nesta etapa do estudo, foram definidas como variáveis do hidromódulo as relações de droga/solvente de 1:8, 1:10 e $1: 12$, mantidas constantes nos três procedimentos extrativos.

Parte das soluções extrativas foi reservada para análises químicas e o restante submetido à concentração sob pressão reduzida em rotaevaporador. Para os ensaios biológicos os resíduos secos foram diluídos diretamente em solução tamponada de fosfato (PBS/ $\mathrm{pH}$ : 7,2 ), em concentração final de $5 \mathrm{mg} / \mathrm{mL}$; ou previamente solubilizadas em dimetil sulfóxido (DMSO), obedecendo limite de 0,1\% (GILLIN; REINER; SUFFNESS, 1982). Todas as soluções foram esterilizadas em membrana filtrante de $0,22 \mu \mathrm{m}$, mantidas em frascos estéreis, a $4^{\circ} \mathrm{C}$, para a realização dos ensaios biológicos.

Todos os extratos obtidos foram submetidos à determinação do rendimento (COSȚA, 1994; SIMÕES et al., 2004; FARMACOPÉIA BRASILEIRA, 2010).

\subsection{Análises sensoriais}

Os extratos hidroalcoólicos das folhas de Anacardium occidentale foram submetidos às análises sensoriais de aroma e variação de coIoração (FARMACOPÉIA BRASILEIRA, 2010).

\subsection{Análises químicas}

\subsubsection{Screening químico}

Os extratos hidroalcoólicos das folhas de Anacardium occidentale obtidos por planejamento fatorial (procedimento extrativo e relação de hidromódulo) foram submetidos a métodos de avaliação qualitativos e semiquantitativos dos constituintes químicos (COSTA, 1994; FALKENBERG et al., 2004; MATOS, 2009).

\subsubsection{Quantificação de compostos fenólicos}

\subsubsection{Determinação do teor de polifenóis totais}

As concentrações de polifenóis totais foram obtidas utilizando reagente de Folin-Ciocalteau e $\mathrm{Na}_{2} \mathrm{CO}_{3}$ a 20\%. A leitura foi realizada em espectrofotômetro UV-Vis, a $760 \mathrm{~nm}$. Ácido gálico (Merck@) foi utilizado como padrão, com resultados expressos em porcentagem (\%) (FUNARI; FERRO, 2006; DUTRA et al., 2008).

\subsubsection{Determinação do teor de flavonoides}

As concentrações de flavonoides totais foram obtidas pelo método colorimétrico com solução metanólica de $\mathrm{AlCl}$ 3. A leitura foi reali- 
zada em espectrofotômetro UV-Vis, a $425 \mathrm{~nm}$. Quercitina (Merck $\circledR$ ) foi utilizada como padrão, com resultados expressos em porcentagem (\%) (FUNARI; FERRO, 2006; DUTRA et al., 2008). 2.4.3 Avaliação da atividade antioxidante dos extratos hidroalcoólicos das folhas de Anacardium occidentale L.

Os extratos vegetais foram submetidos ao método fotocolorimétrico in vitro, utilizando o radical livre estável 2,2-difenil-1-picrilhidra-

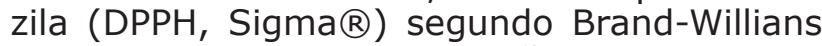
et al. (1995), com modificações. As amostras foram diluídas em diferentes concentrações em metanol P.A (1 a $100 \mu \mathrm{g} / \mathrm{mL}$ ), em seguida adicionados à solução metanólica de DPPH (40 $\mu \mathrm{g} / \mathrm{mL}$ ). Após 30 min de reação em temperatura ambiente ao abrigo da luz, a absorbância de cada solução foi medida em espectrofotômetro UV-VIS (Spectra Max plus 384) a $517 \mathrm{~nm}$. Padrões de ácido gálico, elágico e ascórbico foram usados como controle positivo, nas mesmas condições das amostras. A percentagem de descoloração do radical DPPH foi obtida com a equação: Atividade antioxidante

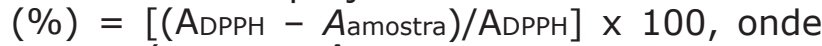
ADPPH é a absorbância do DPPH (controle negativo) e Aamostra é a absorbância do radical na presença dos extratos ou dos padrões.

\subsection{Avaliação da atividade giardicida in vitro dos extratos hidroalcoólicos das fo- Ihas de Anacardium occidentale $L$.}

Cepas axênicas de Giardia lamblia, linhagem Portland-1 (ATCC 30888), foram mantidas em meio TYI-S-33 modificado, enriquecido com bile bovina e suplementado com soro bovino inativado, em tubos de vidro, mantidos em estufa a $37^{\circ} \mathrm{C}$ (DIAMOND; HARLOW; CUNNICK, 1978; KEISTER, 1983; DI CARLO et al., 1999). Para manutenção e preservação in vitro das cepas, as culturas foram examinadas diariamente em microscópio invertido, verificando crescimento, atividade e grau de aderência dos trofozoítos à parede do tubo. Repiques foram realizados a cada 96 horas, correspondendo à fase exponencial de crescimento (ROCHA, 2003; AMARAL, 2007).

$O$ ensaio da atividade giardicida in vitro foi realizado segundo Cedillo-Rivera e Muñoz (1992), Cedillo-Rivera, Ramírez e Muñoz (1992) e Calzada et al. (1999), com modificações (AMARAL, 2007). Alíquotas das soluções estoque dos extratos das folhas de Anacardium occidentale ( $5 \mathrm{mg} / \mathrm{mL}$ ) foram adicionadas em

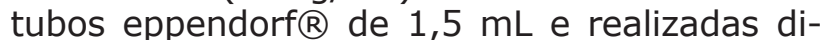
luições seriadas em meio TYI-S-33 modificado, resultando em concentrações finais de 500,0; 100,$0 ; 20,0$ e 4,0 $\mu \mathrm{g} / \mathrm{mL}$. A partir da determinação da curva de crescimento e definição das fases, inóculo de $5 \times 10^{3}$ trofozoítos/mL obtido de cultura em fase logarítmica de crescimento, foi distribuído nos tubos eppendorf $\circledast$ de $1,5 \mathrm{~mL}$.

As avaliações quantitativas foram realizadas pelo método direto (contagem do número total de trofozoítos vivos em câmara de Neubaeur) e indireto (método colorimétrico com uso de brometo de 3-[4,5-dimetil-tiazol-2-il]-2,5-difenil-tetrazólio - MTT). Os ensaios incluíram controle positivo (metronidazol) e controle negativo (meio TYI-S-33, água e/ou DMSO).

\subsection{Análise estatística}

$\mathrm{Na}$ avaliação da atividade giardicida in vitro, os resultados foram expressos como concentração inibitória de crescimento (CI50), calculados por regressão linear, empregando o programa GraphPad Prism 5.0. A amostra foi testada em triplicata e os experimentos realizados pelo menos duas vezes $(n=6-9)$.

Os teores de compostos fenólicos foram analisados empregando ANOVA, seguidos do teste de Newman-Keuls, onde os valores de $p<0,05$ foram considerados significantes. $\mathrm{Na}$ atividade antioxidante, os resultados são representados pelo valor da CE50, concentração efetiva $50 \%$, ou seja, concentração da amostra necessária para sequestrar $50 \%$ dos radicais DPPH e avaliados empregando análise de variância (ANOVA), seguidos do teste de Newman-Keuls, onde os valores de $p<0,05$ foram considerados significantes. Todos os dados foram analisados pelo Programa GraphPad Prism versão 5.0.

\section{RESULTADOS E DISCUSSÃO}

Foi observada variação expressiva de cor entre os extratos, sendo comprovada cor castanho mais intensa nos extratos obtidos por maceração e percolação.

A extração por percolação nas relações de hidromódulo de 1:10 e 1:12 possibilitou soluções extrativas com melhores rendimentos (tabela 1), o que pode ser justificado pela dinâmica desse procedimento com difusão do líquido extrator mais acentuada do que na maceração (PRISTA; ALVEZ; MORGADO, 1996 ; NAVARRO, 2005).

Os resultados da prospecção química nos extratos hidroalcoólicos das folhas de Anacardium occidentale, através de testes qualitativos, demonstram resultados positivos para alcaloides, compostos fenólicos, saponinas, taninos hidrolisáveis, esteroides, flavononóis, catequinas e flavononas, sendo comprovados resultados negativos para cumarinas, heterosídeos cianogênicos, taninos condensados, triterpenos, antocianinas, antocianidinas, flavonas, flavonóis, xantanas, chalconas e leucoantocianidinas (tabela 2).

$\mathrm{Na}$ avaliação da eficácia do procedimento extrativo e relação de hidromódulo desses extratos, constatamos que compostos fenólicos, alcaloides, taninos hidrolisáveis, esteróides, flavononóis, catequinas e flavononas sofrem influência dessas variáveis em relação à avaliação semiquantitativa (tabela 2).

Na quantificação de polifenóis totais e flavonoides realizados nos extratos em análise, evidenciamos variação quantitativa desses constituintes, comprovando resultados mais expressivos na relação de hidromódulo 1:10, 
Tabela 1 - Rendimento (\%) dos extratos hidroalcoólicos das folhas de Anacardium occidentale L. obtidos por maceração, percolação e em aparelho de Soxleht com diferentes relações de hidromódulo

\begin{tabular}{l|l}
\hline EXTRATOS HIDROALCOÓLICOS/RELAÇÕES DE HIDROMÓDULO & RENDIMENTO TOTAL (\%) \\
\hline M8 & 3,92 \\
\hline M10 & 4,42 \\
\hline M12 & 4,09 \\
\hline P8 & 4,01 \\
\hline P10 & 5,64 \\
\hline P12 & 5,40 \\
\hline S10 & 0,14 \\
\hline S12 & 0,15 \\
\hline
\end{tabular}

Extratos hidroalcoólicos das folhas de Anacardium occidentale L. obtidos por diferentes procedimentos extrativos e relações de hidromódulo. Extratos obtidos por maceração com hidromódulo 1:8 (M 1:8), 1:10 (M 1:10) e 1:12 (M 1:12), percolação com hidromódulo 1:8 (P 1:8), 1:10 (P 1:10) e 1:12 (P 1:12) e em aparelho de Soxhlet com hidromódulo 1:8 (S 1:8), 1:10 (S 1:10) e $1: 12$ (S $1: 12)$.

Tabela 2 - Avaliação qualitativa e semiquantitativa dos constituintes químicos nos extratos hidroalcoólicos das folhas de Anacardium occidentale L. obtidos por maceração, percolação e Soxhlet com diferentes relações de hidromódulo

\begin{tabular}{|c|c|c|c|c|c|c|c|c|c|}
\hline \multirow{3}{*}{ METABÓLITOS SECUNDÁRIOS } & \multicolumn{9}{|c|}{ EXTRATO HIDROALCOÓLICO/RELAÇÃO DE HIDROMÓDULO } \\
\hline & \multicolumn{3}{|c|}{ MACERAÇÃO } & \multicolumn{3}{|c|}{ PERCOLAÇÃO } & \multicolumn{3}{|c|}{ SOXHLET } \\
\hline & M1:8 & M1:10 & $M 1: 12$ & $\mathrm{P} 1: 8$ & $\mathrm{P} 1: 10$ & $\mathrm{P} 1: 12$ & $\mathrm{~S} 1: 8$ & $\mathrm{~S} 1: 10$ & $\mathrm{~S} 1: 12$ \\
\hline ácidos orgânicos & - & - & - & - & - & - & - & - & - \\
\hline alcaloides & ++ & + & + & + & + & - & - & - & - \\
\hline compostos fenólicos & +++ & +++ & +++ & +++ & +++ & +++ & ++ & ++ & ++ \\
\hline cumarinas & - & - & - & - & - & - & - & - & - \\
\hline heterosídeos cianogênicos & - & - & - & - & - & - & - & - & - \\
\hline resinas & - & - & - & - & - & - & - & - & - \\
\hline saponinas & + & + & + & + & + & + & + & + & + \\
\hline taninos condensados & - & - & - & - & - & - & - & - & - \\
\hline taninos hidrolisáveis & +++ & +++ & +++ & +++ & +++ & +++ & ++ & ++ & ++ \\
\hline esteroides & ++ & ++ & + & ++ & ++ & ++ & ++ & + & + \\
\hline triterpenos & - & - & - & - & - & - & - & - & - \\
\hline antocianinas, antocianidinas & - & - & - & - & - & - & - & - & - \\
\hline flavonas, flavonóis e xantonas & - & - & - & - & - & - & - & - & - \\
\hline chalconas & - & - & - & - & - & - & - & - & - \\
\hline flavononóis & +++ & +++ & +++ & +++ & +++ & +++ & + & + & + \\
\hline leucoantocianidinas & - & - & - & - & - & - & - & - & - \\
\hline catequinas & + & + & + & + & + & + & - & - & - \\
\hline flavononas & + & + & + & + & + & + & - & - & - \\
\hline
\end{tabular}

Extratos hidroalcoólicos das folhas de Anacardium occidentale L. obtidos por diferentes procedimentos extrativos e relações de hidromódulo. Extratos obtidos por maceração com hidromódulo 1:8 (M 1:8), 1:10 (M 1:10) e 1:12 (M 1:12), percolação com hidromódulo 1:8 (P 1:8), 1:10 (P 1:10) e 1:12 (P 1:12) e em aparelho de Soxhlet com hidromódulo $1: 8$ (S 1:8), 1:10 (S 1:10) e 1:12 (S 1:12).

obtidos por percolação e maceração, respectivamente (tabela 3 ). Esses resultados evidenciam que os procedimentos a frio (maceração e percolação) possibilitaram resultados mais expressivos, embora a literatura enfatize que a temperatura do processo extrativo possa influenciar de maneira positiva, ocasionando aumento da solubilidade de determinado princípio ativo, diminuição da viscosidade do solvente e aumento da velocidade de difusão; motivo para que os processos de extração a quente são sempre mais rápidos do que aqueles realizados à temperatura ambiente (PRISTA; ALVES; MORGADO, 1996; SIMÕES, et al., 2004 ; MIGLIATO et al., 2011).

A atividade antioxidante dos extratos hidroalcoólicos das folhas de Anacardium occidentale foi mais expressiva nas amostras submetidas à percolação nas relações de hidromódulo de 1:10 e 1:12 (tabela 4). 
Tabela 3 - Teor de polifenóis e flavonoides nos extratos hidroalcoólicos das folhas de Anacardium occidentale L. obtidos por diferentes procedimentos extrativos e relações de hidromódulo

\begin{tabular}{c|c|c}
\hline $\begin{array}{c}\text { EXTRATOS HIDROALCOÓLICOS/ } \\
\text { RELAÇÕES DE HIDROMÓDULO }\end{array}$ & POLIFENÓIS TOTAIS (\%) & FLAVONOIDES (\%) \\
\hline M8 & $16,70^{*} \pm 0,005$ & $3,55^{*} \pm 0,006$ \\
\hline M10 & $17,23^{*} \pm 0,003$ & $4,29 \pm 0,003$ \\
\hline M12 & $16,31^{*} \pm 0,003$ & $3,64^{*} \pm 0,003$ \\
\hline P8 & $17,48^{*} \pm 0,004$ & $2,15^{*} \pm 0,007$ \\
\hline P10 & $21,05 \pm 0,002$ & $3,9 * \pm 0,009$ \\
\hline P12 & $19,92^{*} \pm 0,001$ & $2,8^{*} \pm 0,005$ \\
\hline S8 & $14,15^{*} \pm 0,008$ & $1,40^{*} \pm 0,009$ \\
\hline S10 & $13,23^{*} \pm 0,007$ & $1,24 * \pm 0,010$ \\
\hline S12 & $12,18^{*} \pm 0,003$ & $1,18^{*} \pm 0,008$ \\
\hline
\end{tabular}

Extratos hidroalcoólicos das folhas de Anacardium occidentale L. obtidos por diferentes procedimentos extrativos e relações de hidromódulo. Extratos obtidos por maceração com hidromódulo 1:8 (M 1:8), 1:10 (M 1:10) e 1:12 (M 1:12), percolação com hidromódulo 1:8 (P 1:8), 1:10 (P 1:10) e 1:12 (P 1:12) e em aparelho de Soxhlet com hidromódulo 1:8 (S 1:8), 1:10 (S 1:10) e 1:12 (S 1:12). * indica diferença significativa em relação à P10 (quantificação de polifenóis totais) e M10 (quantificação de flavonoides), ( $p$ $<0,05)$, ANOVA seguido de Newman-Keuls.

Tabela 4 - Atividade antioxidante expressa em valor de CE50 dos extratos hidroalcoólicos das folhas de Anacardium occidentale $L$. obtidos por maceração, percolação e Soxhlet com diferentes relações de hidromódulo

\begin{tabular}{l|l}
\hline EXTRATOS HIDROALCOÓLICOS/RELAÇÕES DE HIDROMÓDULO & CE50 $(\mu \mathrm{g} / \mathrm{mL})$ \\
\hline M8 & 33,90 \\
\hline M10 & 38,87 \\
\hline M12 & 35,45 \\
\hline P8 & 36,34 \\
\hline P10 & 31,44 \\
\hline P12 & 31,87 \\
\hline S10 & 49,68 \\
\hline S12 & 50,80 \\
\hline
\end{tabular}

Extratos hidroalcoólicos das folhas de Anacardium occidentale L. obtidos por diferentes procedimentos extrativos e relações de hidromódulo. Extratos obtidos por maceração com hidromódulo 1:8 (M 1:8), 1:10 (M 1:10) e 1:12 (M 1:12), percolação com hidromódulo 1:8 (P 1:8), 1:10 (P 1:10) e 1:12 (P 1:12) e em aparelho de Soxhlet com hidromódulo 1:8 (S 1:8), 1:10 (S 1:10) e 1:12 (S 1:12).

O extrato hidroalcoólico das folhas de Anacardium occidentale obtido por percolação, na relação de hidromódulo $1: 10$, por ter apresentado resultados mais expressivos nas análises anteriores, foi selecionado para avaliação da atividade giardicida, sendo evidenciada moderada atividade citotóxica contra Giardia lamblia (CI50: 365,23 $\pm 18,54 \mu \mathrm{g} / \mathrm{mL}$ ), de acordo com escore de Amaral et al. (2006).

Compostos fenólicos (taninos e flavonoides) e esteroides, detectados na prospecção fitoquímica com os extratos hidroalcoólicos das folhas de Anacardium occidentale (tabelas 2 e 3 ), podem justificar a atividade citotóxica contra Giardia lamblia, conforme evidenciaram Amaral et al. (2006) em estudo de revisão de constituintes químicos de origem vegetal, isolados de outras espécies com expressiva atividade giardicida.

\section{CONSIDERAÇÕES FINAIS}

Os resultados desse estudo permitem evidenciarmos que os extratos hidroalcoólicos das folhas de Anacardium occidentale $L$. apresentaram expressiva atividade antioxidante e moderada atividade citotóxica contra trofozoítos de Giardia lamblia, o que pode ser justificada pela presença de classes de metabólitos secundários de interesse farmacológico constatada nas análises químicas. Foi, ainda, comprovado que procedimentos extrativo e hidromódulo são variáveis que influenciam na obtenção dos extratos e, consequentemente, nos seus rendimentos e atividades antioxidante e giardicida.

\section{REFERÊNCIAS}

ADAM, R.D. Biology of Giardia lamblia. Clinical Microbiology Reviews, v.14, p.447-475, 2001. 
AGRA, M.F.; FRANÇA, P.F.; BARBOSAFILHO, J.M. Synopsis of the plants known as medicinal and poisonous in Northeast of Brazil. Revista Brasileira de Farmacognosia, v. 17, p. 114-140, 2007.

\section{AMARAL, F.M.M. Potencial giardicida} de espécies vegetais: aspectos da etnofarmacologia e bioprospecção. 2007. 346f. Tese (Doutorado em Produtos Naturais e Sintéticos Bioativos) - Universidade Federal da Paraíba, João Pessoa, 2007.

AMARAL, F.M.M. et al. Plants and chemical constituents with giardicidal activity. Revista Brasileira de Farmacognosia, v.16(supl.), p.696-720, 2006.

ARGÜELLO-GARCÍA, R. et al. Variability and variation in drug susceptibility among Giardia duodenalis isolates and clones exposed to 5nitroimidazoles and benzimidazoles in vitro.

Journal of Antimicrobial Chemotherapy, v.54, p.711-721, 2004.

BRASIL. Ministério da Saúde. Agência Nacional de Vigilância Sanitária. Portaria ANVISA-MS no 971, de 03 de maio de 2006. Aprova a Política Nacional de Práticas Integrativas e Complementares (PNPIC) no Sistema Único de Saúde. Diário Oficial [da] República Federativa do Brasil, Brasília, DF, 04 maio 2006.

BARBOSA-FILHO, J.M. et al. Plants and their active constituents from South, Central, and North America with hypoglycemic activity. Revista Brasileira de Farmacognosia, v. 15, p. 392-413, 2005.

BARBOSA-FILHO, J.M. et al. Natural products inhibitors of the enzyme acetylcholinesterase. Revista Brasileira de Farmacognosia, v. 16, p. 258-285, 2006.

BARROS, L.M.; CRISÓSTOMO, J.R.

Melhoramento genético do cajueiro. In: ARAÚJO, J.P.P.; SILVA, V.V. Cajucultura: modernas técnicas de produção. Fortaleza: EMBRAPA \CNPAT, 1995. p.73-96.

BARROS, L. M. Melhoramento. In: LIMA, V. P. M. S. A cultura do cajueiro no nordeste do Brasil. Fortaleza: Banco do Nordeste do Brasil/ETENE, 1988b. p.321-355.

BARROS NETO, B.; SCARMINIO, I.S.; BRUNS, R.E. Planejamento e otimização de experimentos. Campinas: Editora da Unicamp, 1995. v. 1. 300 p.

BOTSARIS, S.A. Fitoterapia chinesa e plantas brasileiras. São Paulo: Ícone, 1995. 550p.

BRAND-WILLIAMS, W.; CUVELIER, M. E.; BERSET, C. Use of a free radical method to evaluat antioxidant activity. Food Science and Technology, v. 28, p.25-30, 1995.

CALZADA, F. et al. Geranins A and B, New Antiprotozoal A-Type Proanthocyanidins from Geranium niveum. Journal of Natural Products, v. 62, p.705-709, 1999.
CEDILLO-RIVERA, R.; RAMÍREZ, A.;

MUÑOZ, O. A rapid colorimetric assay with the tetrazolium salt MTT and phenazine methosulfate (PMS) for viability of Entamoeba histolytica. Archives of Medical Research, v.23, p.59-61, 1992.

CEDILLO-RIVERA, R.; MUÑOZ, O. Invitro susceptibility of Giardia lamblia to albendazole, mebendazole and other chemotherapeutic agents. Journal of Medical Microbiology, v.37, p.221-224,1992.

COSTA, A.F. Farmacognosia. 4.ed. Lisboa: Fundação Calouste Gulbenkian, 1994. v.II. $1023 \mathrm{p}$.

DE CARLI, G. A. Parasitologia Clínica: seleção de métodos e técnicas de laboratório para o diagnóstico das parasitoses humanas. São Paulo: Editora Atheneu, 2001. 810p.

DI CARLO, G. et al. Flavonoids: Old and new aspects of a class of natural therapeutic drugs. Life Science. v. 65, p. 337-53, 1999.

DIAMOND, L.S.; HARLOW, D.R.; CUNNICK, C.C. A new medium for the axenic cultivation of Entamoeba histolytica and other Entamoeba. Transactions of the Royal Society of Tropical Medicine and Hygiene, v.72, p.431-432, 1978.

DUQUE, J.G. Sobre o cajueiro (Anacardium occidentale L.), sua cultura e importância econômica. Boletim da Sociedade Cearense Agronômica, v.3, p.33-36, 1962.

DUTRA, R. P. et al. Avaliação farmacognóstica de geoprópolis de Melipona fasciculata Smith (tiúba) em municípios da Baixada maranhense, Brasil. Revista Brasileira de Farmacognosia, v. 18, n. 4, p. 557-562, 2008.

ELISABETSKY, E. Etnofarmacologia como ferramenta na busca de substâncias ativas. In: SIMÕ̃E, C. M. O. et al. (Org.). Farmacognosia: da planta ao medicamento. Porto Alegre: UFRGS, 2004. p. 91-103.

FALCÃO, H.S. et al. Review of the plants with anti-inflammatory activity studied in Brazil. Revista Brasileira de Farmacognosia, v. 15, p. 381-391, 2005.

FALKENBERG, M.B.; SANTOS, R.I.; SIMÕES, C.M.O. Introdução a fitoquímica experimental. In: SIMÕES, C.O.M. et al. Farmacognosia: da planta ao medicamento. 5.ed. rev. ampl., primeira reimpressão. Porto Alegre/ Florianópolis: Ed. Universidade/UFRGS/Ed. da UFSC, 2004. p.163-179.

FARMACOPÉIA BRASILEIRA. Agência Nacional de Vigilância Sanitária. 5. ed. Brasília, DF: ANVISA, 2010.

FUNARI, C.S.; FERRO, V.O. Análise de Própolis. Ciência e Tecnologia de Alimentos, v. 26, p. 171-178, 2006. 
GILLIN, F. D.; REINER, D. S.; SUFFNESS, M. Bruceantin, a potent amoebicide from a plant. Brucea antidysenterica. Antimicrobial Agents and Chemotherapy, v.22, p.342-345, 1982.

HARRIS, J.C.; PLUMMER, S.; LLOYD, D. Antigiardial drugs. Applied Microbiology Biotechnology, v.57, p.614-619, 2001.

HERESI, G.P.; MURPHY, J.R.; CLEARY, T.G. Giardiasis. Seminars in Pediatric Infectious Diseases, v.11, p.89-195, 2000.

JOHNSON, D.V. The botany, origin and spread of cashew (Anacardium occidentale L.). Journal of plantation crops, Kasaragod, v.1, n.1, p.1-7, 1973.

KAMTCHOUING, P. et al. Protective role of Anacardium occidentale extract against streptozotocin-induced in rats. Journal of Ethnopharmacology, v. 62, p. 95-99, 1998.

KEISTER, D.B.; Axenic culture of Giardia lamblia in TYI-S-33 medium supplemented with bile. Transactions of the Royal Society of Tropical Medicine and Hygiene, v.77, p.487-488, 1983.

KUBO, I.; KINST-HORI, I.; YOKOKAWA, Y. Tyrosinase inhibitors from Anacardium occidentale fruits. Journal of Natural Products, v. 57, p. 545-551, 1994.

LAPA, A. J. et al. Farmacologia e Toxicologia de produtos naturais. In: SIMÕES, C.O.M. et al. Farmacognosia: da planta ao medicamento. 5.ed. rev. ampl. Porto Alegre. Ed. Universidade/UFRGS. Florianópolis: Ed. da UFSC, 2004. p.247-262.

LIMA, V. P. M. S. A cultura do cajueiro no nordeste do Brasil. Banco do Nordeste do Brasil. Fortaleza: ETENE, 1988.

MATOS, F.J.A. Introdução à fitoquímica experimental. 2.ed. Fortaleza: Edições UFC, 2009. $143 \mathrm{p}$.

MIGLIATO, K. F. et al. Planejamento experimental na otimização da extração dos frutos de Syzygium cumini (L.) Skeels. Quimica Nova, v.34, n.4, p.695-699, 2011.

MITCHELL, J.D.; MORI, S.A. The cashew and its relatives (Anacardium: Anacardiaceae). Memories on the New York Botanical Garden, v.42, p.1-76, 1987.

MOLYNEUX, P. The use of the stable free radical diphenylpicrylhydrazyl (DPPH) for estimating antioxidant activity. Songklanakarin Journal of Science and Technology, v.26, n.2, p.211-9, 2004.

MORTON, J.F. The cashew's brighter future. Economic Botany, New York, v. 15, n. 1, p. 57-78, 1961.

MORAIS, S.M. et al. Plantas medicinais usadas pelos índios Tapebas do Ceará. Revista Brasileira de Farmacognosia, v.15, p. 169-177, 2005.
NAVARRO, D. Estudo químico, biológico e farmacológico das espécies Allamanda blanchetti e Allamanda schottii na obtenção de moléculas bioativas de potencial terapêutico. 2005. $293 \mathrm{f}$. Tese (Doutorado em Química) - Universidade Federal de Santa Catarina, Florianópolis, 2005.

NEVES, D.P. Parasitologia humana. 11.ed. São Paulo: Ed. Atheneu, 2005. 494p.

OLAJIDE, O. A. et al. Effects of Anacardium occidentale stem bark extracton in vivo inflammatory models. Journal of Ethnopharmacology, v. 95, p. 139-142, 2004.

OLIVEIRA, F. DE; AKISUE, G.; AKISUE, M.K. Farmacognosia. São Paulo: Atheneu, 1991. 412p.

PINTO, A.C. et al. Produtos naturais: atualidade, desafios e perspectivas. Química Nova, v.25, supl.1, p.45-61, 2002.

PRISTA, L. N.; ALVES, A. C.; MORGADO, R. Tecnologia farmacêutica, 4 ed. Fundação Calouste: Lisboa Gulbenkian, 1996.

ROCHA, M.O. Giardia duodenalis: axenização e caracterização de três isolados do Brasil, empregando parâmetros biológicos, bioquímicos, imunológicos e moleculares. 2003. 112f. Tese (Doutorado em Ciências Farmacêuticas) - Universidade Federal de Minas Gerais, Belo Horizonte, 2003.

SIXEL, P. J.; PECINALLI, N. R. Características farmacológicas gerais das plantas medicianis. Infarma, v. 16, n.13-14, p. 74-77, 2005.

SIMÕES, C.O.M. et al. Farmacognosia: da planta ao medicamento. 5.ed. rev. ampl. Porto Alegre: Ed. Universidade/UFRGS, Florianópolis: Ed. da UFSC, 2004. 1102p.

SOGAYAR, M.I.T.L.; GUIMARÃES, S. Giardia lamblia. IN: Neves, D.P.; Melo, A.L.; Genaro, O.; Linardi, P.M. Parasitologia Humana. 10 ed. São Paulo: Ed. Atheneu, 2005. 428p. 2005.

THOMPSON, R.C.A.; HOPKINS, R.M.; HOMAN, W.L. Nomenclature and genetic groupings of Giardia infecting mammals. Parasitology Today, v.1, p.210-213, 2000.

UPCROFT, et al. Antigen expression fron the ribosomal dna repeat unit of Giardia intestinalis. Nucleic Acids research. v. 18, n. 7077, p. 70-81, 1990.

UPCROFT, J. A. et al. Efficacy of new 5-nitroimidazoles against metronidazolesusceptible and resistant Giardia, Trichomonas and Entamoeba spp. Antimicrobial Agents and Chemotherapy, v. 43, p.73-76, 1999.

UPCROFT, J.A.N.; CHEN; UPCROFT, $P$. Mapping variation in chromosome homologues of different giardia strains. Molecular and Biochemical Parasitology. v.76, p.135-143, 1996. 
UPCROFT, J.A.; HEALEY, A.; UPCROFT, P. Chromosomal duplication in Giardia duodenalis. International Journal For Parasitology. v.23, p.609-616, 1993.

VON HERTWIG, I. F. Plantas aromáticas e medicinais: plantio, colheita, secagem e comercialização. 2.ed. São Paulo: Ícone, 1991. 414 p.
YUNeS, R. A.; CALIXTO, J.B. (Org.) Plantas medicinais sob a ótica da química medicinal moderna. Chapecó: Argos, 2001. 500p.

WHO. Partners for Parasite Control. 2009.

Disponível em: <http://www.who.int/ wormcontrol/en>. Acesso em: 10 fev. 2013. 